\title{
A TEST VERIFIED MODEL DEVELOPMENT STUDY FOR A NUCLEAR WATER CHILLER USING THE SEISMIC QUALIFICATION ANALYSIS AND TEST
}

\author{
UKHWAN SUR \\ School of Mechanical and Automotive Engineering, Halla University \\ Wonju, 220-712, Korea \\ *Corresponding author. E-mail : uhsur@halla.ac.kr
}

Received January 18, 2011

Accepted for Publication March 11, 2011

This paper is a study on a nuclear water chiller. It presents a test-verified finite element model of a water chiller to be used at a Nuclear Power Plant. The test-verified model predicts natural frequencies within 5\% for all major modes below 50 Hz. This model accurately represents the dynamic characteristics of the actual hardware and is qualified for its use in the final stress analysis for seismic verification.

KEYWORDS : Equipment Qualification; Finite Element Method; Modal Analysis; Seismic Qualification; Water Chiller

\section{INTRODUCTION}

This paper details the seismic analysis performed on the water chiller for Beaver Valley Nuclear Power Station in the U.S.A. [1].

The overall dimensions of the chiller unit are 15 feet 3 inches long by 7 feet wide by 8 feet 10 inches tall. The shipping weight of the unit is 27,940 pounds, and the operating weight is 31,900 pounds. The unit shown in Fig. 1 consists of an evaporator, a condenser, a two-stage centrifugal compressor and an electric motor drive, an economizer, a control panel and related instrumentation, related piping, a lubricating oil system, and refrigerant and oil.

The evaporator is a flooded shell and tube. It consists of a carbon steel cylindrical shell which is 143.7 inches long, 42.75 inches in diameter, and 0.35 inches thick. A carbon steel tube sheet is welded to each end of the cylinder with a partial copper tube bundled in between the tube sheet. Each tube sheet is connected to a ground support. A carbon steel elliptical head (water box) having a $0.35-$ inch wall is flange-bolted to each end of the evaporator. One head is equipped with two connections (nozzles), one inlet pipe and one outlet pipe, which are 10 inches in diameter. The evaporator shell has a refrigerant liquid inlet connection and a vapor outlet connection.

The condenser consists of a carbon steel cylindrical shell 143.7 inches long, 28 inches in diameter, and 0.24 inches thick. A carbon steel tube sheet is welded to each end of the cylinder with a copper tube bundle between the tube sheets. Each tube sheet is connected to the ground support and welded to the tube sheets of the evaporator. A carbon steel elliptical head (water box), having a $0.24-$ inch wall thickness, is flange-bolted to each end of the condenser. One head is equipped with two connections (nozzles), one inlet pipe and one outlet pipe 8 inches in diameter.

The safety-related water chiller units will be used in the Nuclear Power Plant inside the primary auxiliary building at a seaside location. The chillers will supply demineralized chilled water of $42^{\circ} \mathrm{F}$, with a temperature rise of approximately $9^{\circ} \mathrm{F}$, to the safety-related cooling coils of the control room supply AHU, ESF switch gear and equipment room AHU, and the safety-related cubicle coolers of the primary auxiliary building and fuel building during normal, shutdown, and accident conditions.

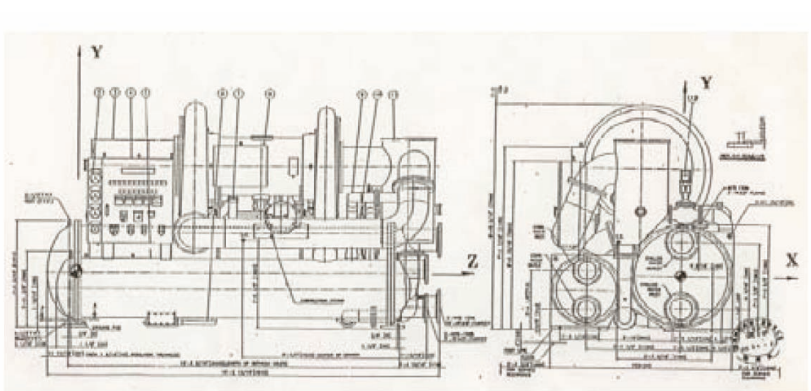

Fig. 1. Water Chiller Assembly 
These chiller units are to be qualified for seismic category 1 in accordance with the customer's specification N. 9-132-m848 and per Section III, Division 1 of the ASME Boiler and Pressure Vessel Code [2], and Section 1.5 and 1.6 of the AISC Steel and Construction Manual [3].

A finite element model of the chiller unit is constructed from the customer's drawings. The lumped mass and stiffener approach using the COSMOSM finite element code [4] is applied for the static, eigenvalue, and dynamic analysis. The applied loads to the unit are Deadweight, Pressure, Thermal, Nozzle, and Seismic.

This paper presents the test-verified finite model of a water chiller. Math models used in the stress analysis of the structural/mechanical components for use in nuclear power plants are usually verified by modal testing. For this purpose, the test results are assumed to be correct and the math model is tuned to closely correlate with the test results.

The primary objective of the effort presented here is to construct a finite element model of the chiller assembly, perform preliminary eigenvalue analysis to obtain all natural frequencies and mode shapes below $50.0 \mathrm{~Hz}$, select optimum accelerometer locations based on the results of the preliminary analysis, perform a modal survey test on the chiller, obtain natural frequencies and mode shapes for all modes below $50.0 \mathrm{~Hz}$, and correlate the analysis and test frequencies to within 5\%.

\section{NORMAL MODE ANALYSIS METHODOLOGY}

The computation of natural frequencies and mode shapes is known as modal or normal modes analysis. The finite element system of equations for dynamical systems can be written as

$$
[M]\{\ddot{u}\}+[C]\{u\}+[K]\{u\}=\{f(t)\},
$$

where $[\mathrm{M}]$ is the mass matrix, $[\mathrm{C}]$ is the damping matrix, and $[\mathrm{K}]$ is the stiffness matrix. For free vibrations, the above equation takes the form

$$
[M]\{\ddot{u}\}+[C]\{\dot{u}\}+[K]\{u\}=0 .
$$

When undamped linear elastic structures are initially displaced into a certain shape, they will oscillate indefinitely with the same mode shape but exhibit varying amplitudes. The oscillation shapes are called the mode shapes and the corresponding frequencies are called natural frequencies. The term modal analysis has been used throughout this manual for the study of natural frequencies and mode shapes. For undamped linear elastic structures, the above equation reduced to

$$
[M]\{\ddot{u}\}+[K]\{u\}=0 .
$$

With no externally applied loads, the structure is assumed to vibrate freely in a harmonic form defined by

$$
u(t)=\phi \sin (\omega t+\theta),
$$

which leads to the eigenvalue problem,

$$
\left[[K]-\omega^{2}[M]\right]\{\phi\}=0,
$$

where $\omega$ is the natural frequency and $\phi$ is the corresponding mode shape of the structure.

\section{PRETEST ANALYSIS AND MODAL SURVEY TEST}

\subsection{Finite Element Model}

The model for this chiller is modeled using a finite element method that has a shell, a beam, a pipe, an elbow, and mass elements. The major equipment is represented by beams and appropriate lumped mass systems based on customer-supplied weight data. The weight of the miscellaneous equipment is distributed by adjusting the density of the structural elements [2].

\subsection{Test Requirements}

The test requirements are described in the applicable paragraphs of Wyle Laboratories's Qualification Plane No. 41184-00 dated October 16, 1991, Revision B dated September, 1992, which is contained in Reference [1].

\subsection{Pretest Analysis}

This model was used for the pretest frequency analysis with a minor modification. The weight of the refrigerant (Freon) was removed from the model to accurately represent the test conditions. The boundary conditions of the seismic model, fixed in the three global translational directions and two rotational directions about the $\mathrm{X}$ and $\mathrm{Z}$ directions, were kept intact. Eigenvalue analysis was performed and modes up to $50 \mathrm{~Hz}$ were extracted using the Lanczos technique. An isometric view of the model is shown in Fig. 2. Results of the pretest frequency analysis are tabulated in Table 1.

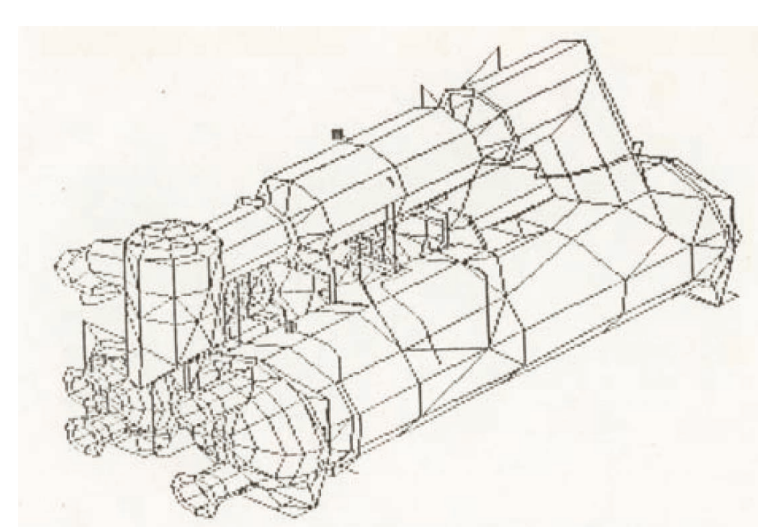

Fig. 2. Mathematical Model of the Water Chiller Assembly 
Table 1. Frequency Results of the Pretest Analysis

\begin{tabular}{|c|c|c|c|}
\hline Mode Number & Natural Freq. (Hz) & $\begin{array}{l}\text { Status and Principal } \\
\text { Direction of Mode }\end{array}$ & Mode Description \\
\hline 1 & 2.25 & $\mathrm{X}$ & Control Box \\
\hline 2 & 5.32 & LOCAL & - \\
\hline 3 & 6.36 & $\mathrm{X}$ & All Upper Components \\
\hline 4 & 10.89 & $\mathrm{X}$ & Separator \\
\hline 5 & 11.82 & $\mathrm{Z}$ & Separator \\
\hline 6 & 11.89 & $\mathrm{X}$ & Separator-Higher Mode \\
\hline 7 & 17.46 & $\mathrm{X}$ & System \\
\hline 8 & 21.82 & $X$ & Main Suction Pipe, Motor \\
\hline 9 & 24.39 & $\mathrm{X}$ and $\mathrm{Z}$ & Main Suction Pipe, Motor, Economizer, Crossover Pipe \\
\hline 10 & 29.73 & $\mathrm{Z}$ & Main Suction pipe, Motor, Gas Return Pipe, Economizer \\
\hline 11 & 34.60 & $\mathrm{Y}$ & Condenser Outlet Pipe \\
\hline 12 & 37.77 & $\mathrm{Z}$ & System \\
\hline 13 & 11.82 & $\mathrm{Z}$ & Separator \\
\hline 14 & 44.96 & $\mathrm{X}$ & Condenser, Economizer, Low Pressure Inlet Nozzle, Oil Tank \\
\hline 15 & 48.57 & $\mathrm{X}, \mathrm{Y}$ and $\mathrm{Z}$ & System \\
\hline 16 & 52.30 & $\mathrm{Z}$ & Insides of Evaporator, Crossover Pipe \\
\hline
\end{tabular}

\subsection{Modal Survey Test}

The modal survey test of the water chiller took place at Wyle Laboratories Dynamics Facility. The unit was rigidly mounted to a 30-foot square, 250,000-pound concrete reaction mass. The four feet of the chiller were mounted to 2-inch thick carbon steel plates with 1.5-inch bolts. The 2 -inch plates were then rigidly welded to embedded steel beams in the concrete reaction mass.

The chiller was instrumented with 40 accelerometers as shown in Fig. 3. The location of the accelerometers were selected according to the results of the pretest analysis and the size and mass of the selected components. Engineering judgment was used to optimize the number and location of the accelerometers and yet extract all the important modes. Small components with little mass were ignored since their contribution to the overall system behavior were judged to be insignificant. A 100.0 forcepound electrodynamic shaker was suspended from the building overhead crane and hard mounted to the drive point on the chiller. Accelerometer number 1 was designated to represent the drive point in all test configurations. Prior to the test, both the evaporator and the condenser were filled with water. However, there was no refrigerant in the chiller at the time of the test.

The modal testing of the water chiller was performed using a Hewlett-Packard (Model 423A) Structural Dynamic Analyzer. Data acquisition was accomplished by exiting the structure with the electrodynamic shaker applying random signals, and measuring both the input force and the output structural response at each accelerometer location. All modes with frequencies between 0 to 100 $\mathrm{Hz}$ were extracted during the test. The natural frequencies and mode shapes of interest, between 0 to $50 \mathrm{~Hz}$, are as shown in Table 2.

\section{POSTTEST ANALYSIS}

The predicted analytical and measured test frequencies with the same mode shape characteristics were compared between 0 to $50 \mathrm{~Hz}$. The percentage of error in the predicted natural frequencies was calculated and compared to the evaluation criteria. The analytical model was revised accordingly to correct unacceptable differences and to extract the missing modes present in the test results. 

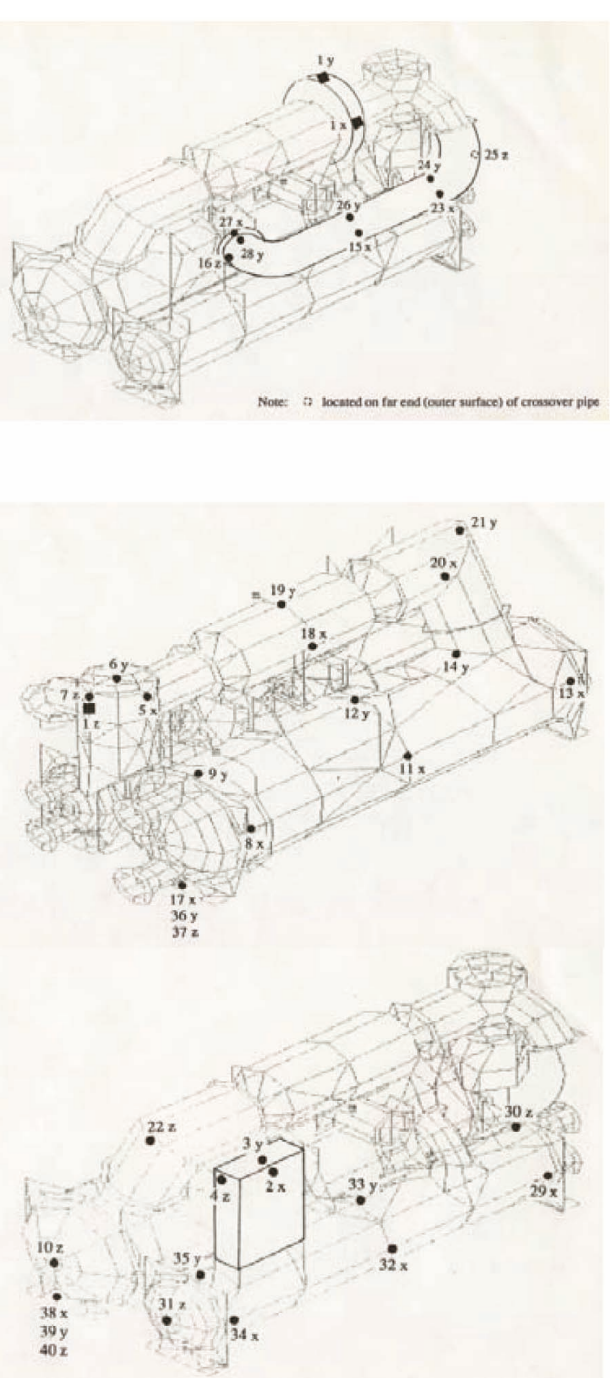

Fig. 3. Location of Accelerometers

Table 2. Frequency Results of the Modal Test

\begin{tabular}{c|c|c|c}
\hline $\begin{array}{c}\text { Mode } \\
\text { Number }\end{array}$ & $\begin{array}{c}\text { Natural } \\
\text { Frequency(Hz) }\end{array}$ & $\begin{array}{c}\text { Status and Principal } \\
\text { Direction of Mode }\end{array}$ & $\begin{array}{c}\text { Mode } \\
\text { Description }\end{array}$ \\
\hline 1 & 12.10 & $\mathrm{X}$ & Control Box \\
\hline 2 & 15.75 & $\mathrm{X}$ & System \\
\hline 3 & 23.60 & $\mathrm{Z}$ & System \\
\hline 4 & 32.77 & $\mathrm{X}$ & $\begin{array}{c}\text { Higher System } \\
\text { Mode }\end{array}$ \\
\hline 5 & 36.66 & $\mathrm{X}$ and Y & \begin{tabular}{c} 
System \\
Crossover Pipe \\
Condenser \\
\hline 6
\end{tabular} \\
\hline 42.62 & 44.00 & $\mathrm{X}, \mathrm{Y}$ and Z & System \\
\hline
\end{tabular}

Table 3. Comparison of Test and Pretest Analysis Frequencies

\begin{tabular}{|c|c|c|c|c|c|}
\hline Flexible & Mode No. & Freq. & $(\mathrm{Hz})$ & $\%$ Error & Status \\
\hline & Pretest & & Pretest & (abs.) & \\
\hline Test & Analysis & Test & Analysis & 81.4 & Unacceptable \\
\hline 1 & 1 & 12.1 & 2.25 & & \\
\hline- & 2 & & 5.32 & & \\
\hline-- & 3 & & 6.36 & & \\
\hline- & 4 & & 10.89 & & \\
\hline- & 5 & & 11.82 & & \\
\hline - & 6 & & 11.89 & & \\
\hline 2 & 7 & 15.75 & 17.46 & 10.9 & Unacceptable \\
\hline- & 8 & & 21.82 & & \\
\hline - & 9 & & 24.39 & & \\
\hline 3 & 10 & 23.36 & 29.73 & 27.3 & Unacceptable \\
\hline 4 & - & 32.77 & & & \\
\hline - & 11 & & 34.60 & & \\
\hline- & 12 & & 37.77 & & \\
\hline- & 13 & & 44.96 & & \\
\hline 5 & 14 & 37.16 & 45.66 & 22.9 & Unacceptable \\
\hline - & - & 42.62 & & & \\
\hline 7 & 15 & 44.00 & 48.57 & 9.4 & Unacceptable \\
\hline 8 & - & 50.00 & & & \\
\hline
\end{tabular}

\subsection{Comparison of Measured and Predicted Frequencies}

The comparison of analysis results of the test and pretest, as shown in Table 3, indicate significant differences. The pretest analysis results produced a number of additional modes while missing a few major system modes. To begin with, the control box X-mode was predicted at $2.25 \mathrm{~Hz}$ with a percentage error of 81.4. The first system $X$ and $Z$ modes at 17.46 and $23.6 \mathrm{~Hz}$, respectively, were predicted with an unacceptable percentage of errors.

\subsection{Tuning of the Analysis Model}

Correlation of the pretest analysis and test frequencies was accomplished in several steps [5-7]. To begin with, all rotary inertias which had been incorrectly calculated with respect to the global coordinate system were revised with respect to their local coordinate system. The boundary conditions at the base of the chiller were changed to fixed in the three translational directions only. All rotational 
fixities at the base of the chiller were released. The coupling of these changes resulted in lowering of the first system $\mathrm{X}$ mode to within the acceptable $5 \%$.

The revisions to the control box were twofold. The vertical supporting $\mathrm{C}$-sections had originally been modeled as a composite section to account for the bentplates at their base. The verticals were revised to C-sections only, and the bent-plates were modeled as plate elements. These changes coupled with the revision in rotary inertias resulted in the first X mode to jump above $15 \mathrm{~Hz}$. The other revisions took place within the rigid elements representing the box itself. These elements, numbering four, spanned from the C.G. of the control box lumped mass to the four corners of the verticals. The ends of the rigid elements mounted to the verticals were released in all rotational directions. Finally, the stiffness of the rigid elements were reduced by changing their modulus of elasticity from $1 \times 10^{12}$ to $8 \times 10^{6}$.

Correlation of the remaining modes was simple once the stiffness of the rigid elements used in the remainder of the model was tuned properly. The modulus of elasticity of the rigid elements representing the First and Second Stage Compressors was changed from $1 \times 10^{12}$ to $2 \times 10^{10}$. The modulus of elasticity of all other rigid elements was reduced from $1 \times 10^{12}$ to $1 \times 10^{10}$. The rigid elements connecting the First and Second Stage Compressors were reduced from a 1-inch pipe to a flexible beam. The combination of these revisions resulted in tuning the first system $\mathrm{Y}$ and $\mathrm{Z}$ modes, the second system $\mathrm{X}$ mode, and the remaining modes below $50 \mathrm{~Hz}$. The results of the posttest eigenvalue analysis and their comparison to the test results are tabulated in Tables 4 and 5.

As shown in Tables 4 and 5, the modal test resulted in eight modes versus fifteen predicted by the analysis model. Analysis mode numbers 1, 2, and 7 are those of the Separator and Condenser Outlet Pipe, which were not instrumented for the test due to their light weight.Mode numbers 9, 10, and 12 are higher modes of the Control Box. In order to extract these modes from a modal test, the Control Box would have had to be instrumented with many accelerometers. Mode number 14 is an extensional mode of the Motor and First and Second Stage Compressors. The absence of extensional mode in the test results is attributed to the extensional stiffness of the First and Second Stage Compressors being higher than the value used in the analysis model. A significant number of runs was made to eliminate this mode. However, any change in the stiffness of the compressors would result in detuning of the lower system modes. Since the model's end use is for seismic qualification analysis, and earthquake force input is constant for modes above $33 \mathrm{~Hz}$, then the impact of this mode is deemed to be insignificant.

Table 4. Frequency Results of Posttest Analysis

\begin{tabular}{|c|c|c|c|}
\hline Mode Number & $\begin{array}{c}\text { Natural } \\
\text { Freq. }(\mathrm{Hz})\end{array}$ & $\begin{array}{l}\text { Status and Principal } \\
\text { Direction of Mode }\end{array}$ & Mode Description \\
\hline 1 & 10.89 & $\mathrm{X}$ & Separator \\
\hline 2 & 11.80 & $\mathrm{Z}$ & Separator \\
\hline 3 & 12.59 & $\mathrm{X}$ & Control Box \\
\hline 4 & 15.90 & $\mathrm{X}$ & System \\
\hline 5 & 24.75 & $\mathrm{Z}$ & System \\
\hline 6 & 31.65 & $\mathrm{X}$ & Higher System Mode \\
\hline 7 & 34.04 & Y & Condenser Outlet Pipe \\
\hline 8 & 35.33 & $\mathrm{Y}$ & System \\
\hline 9 & 39.53 & $\mathrm{X}$ & Higher Mode of the Control Box \\
\hline 10 & 39.63 & $\mathrm{X}$ & Control Box, Higher System Mode \\
\hline 11 & 41.55 & $\mathrm{X}$ and $\mathrm{Y}$ & Crossover Pipe. Condenser \\
\hline 12 & 41.77 & $\mathrm{X}$ and $\mathrm{Z}$ & Control Box \\
\hline 13 & 44.45 & $\mathrm{X}, \mathrm{Y}$ and $\mathrm{Z}$ & System \\
\hline 14 & 49.26 & $\mathrm{Z}$ & Extensional Mode of Motor, $1^{\text {st }}$ and $2^{\text {nd }}$ Stage Compressors \\
\hline 15 & 51.19 & $\mathrm{X}$ and $\mathrm{Z}$ & Crossover Pipe, Control Box, Small Movements throughout the System \\
\hline
\end{tabular}


Table 5. Comparison of Test and Posttest Analysis

\begin{tabular}{|c|c|c|c|c|c|}
\hline Flexible & Mode No. & Frequencies & $(\mathrm{Hz})$ & $\%$ Error & Status \\
\hline & Pretest & & Pretest & (abs.) & \\
\hline Test & Analysis & Test & Analysis & & \\
\hline- & 1 & - & 10.89 & - & - \\
\hline- & 2 & - & 11.80 & - & - \\
\hline 1 & 3 & 12.1 & 12.59 & 4.05 & Acceptable \\
\hline 2 & 4 & 15.75 & 15.90 & 0.95 & Acceptable \\
\hline 3 & 5 & 23.60 & 24.75 & 4.87 & Acceptable \\
\hline 4 & 6 & 32.77 & 31.65 & 3.42 & Acceptable \\
\hline- & 7 & - & 34.04 & - & - \\
\hline 5 & 8 & 36.66 & 35.33 & 3.63 & Acceptable \\
\hline- & 9 & - & 39.53 & - & \\
\hline- & 10 & - & 39.97 & - & - \\
\hline 6 & 11 & 42.62 & 41.55 & 2.51 & Acceptable \\
\hline- & 12 & - & 41.77 & - & \\
\hline 7 & 13 & 44.00 & 44.45 & 1.02 & Acceptable \\
\hline- & 14 & - & 49.26 & - & \\
\hline 8 & 15 & 50.00 & 51.19 & 2.38 & Acceptable \\
\hline
\end{tabular}

\section{CONCLUSIONS}

The results of the chiller modal test indicate eight distinct and major modes of vibration between 0 to 50 Hz. Among these are the first fundamental frequencies of the unit in each of the three orthogonal directions, the second $\mathrm{X}$ mode of the unit, and three higher system modes above $40 \mathrm{~Hz}$.

Assuming the test results to be correct, the analysis model is shown to include the same eight modes in the $0 \mathrm{t}$ $50 \mathrm{~Hz}$ frequency range. These modes are further shown to correlate to within the expected $5 \%$. The analysis results also show seven extra modes in the same frequency range. Six of these modes are insignificant in nature, since they are associated with lightweight components such as the Separator and the Control box. The seventh, which occurs at $49.26 \mathrm{~Hz}$, is attributed to the assumptions and approximations incorporated in the analysis model to fully represent the First and Second Stage Compressors. This mode, having a frequency above $33 \mathrm{~Hz}$, will have an impact on the results of the seismic qualification analysis for which the tuned model was prepared.

The test verified finite element model of the water chiller presented in this report satisfies the objectives of this task, and is ready to be incorporated in the final seismic qualification analysis.

\section{REFERENCES}

[1] Wyle Laboratories' Report No. 41380, Seismic Analysis of Water Chiller Beaver Valley Nuclear Power Station in U.S.A., (1991).

[2] ASME Boiler and Pressure Vessel Code, Section III, (1986).

[3] AISC Steel and Construction Manual, (1990).

[4] COSMOSM user's manual, Structural Research and Analysis Corporation, Santa Monica, California, (1990).

[ 5 ] Roark, Raymond J., and Warren C. Young, Formulas for Stress and Strain, $5^{\text {th }}$ Ed., McGraw Hill, (1990)

[6] ASHRAE Handbook, Fundamental, (1981).

[7] Incropera, Frank P., and David P. Dewitt, Fundamentals of Heat and Mass Transfer, $2^{\text {nd }}$ Ed., John Wiley and Sons, (1992). 